\title{
Design and Evaluation of a Three Dimensionally Ordered Macroporous Structure within a Highly Patterned Cylindrical Sn-Ni Electrode for Advanced Lithium Ion Batteries
}

\author{
Yongcheng Jin, Hirokazu Munakata, Naoya Okada, and Kiyoshi Kanamura \\ Department of Applied Chemistry, Graduate School of Urban Environmental Sciences, Tokyo Metropolitan University, \\ 1-1 Minami-ohsawa, Hachioji, Tokyo 192-0397, Japan \\ Correspondence should be addressed to Kiyoshi Kanamura; kanamura@tmu.ac.jp
}

Received 12 January 2013; Accepted 1 April 2013

Academic Editor: Huijun Wu

Copyright (C) 2013 Yongcheng Jin et al. This is an open access article distributed under the Creative Commons Attribution License, which permits unrestricted use, distribution, and reproduction in any medium, provided the original work is properly cited.

\begin{abstract}
A 3-dimensionally ordered macroporous (3DOM) structure within a highly patterned cylindrical Sn-Ni alloy electrode was tailored by using various monodispersed polystyrene (PS) templates via a colloidal crystal templating process coupled with an electroplating process. The pore size and the wall thickness in the "inverse opal" 3DOM structure were increased with increasing the size of the PS template beads used in this study. The electrochemical performance of prepared electrodes was examined in order to reveal the correlation between the rate capability and the 3DOM structure. Except the electrode with $1.2 \mu \mathrm{m}$ pores, the discharge capacities gradually decreased with increasing the current density, showing a capacity conservation ratio of $87 \%$ for the electrode with $0.5 \mu \mathrm{m}$ pores and that of $84 \%$ for the electrode with $3.0 \mu \mathrm{m}$ pores when the current density increased from $0.05 \mathrm{~mA} \mathrm{~cm}^{-2}$ to $2.0 \mathrm{~mA} \mathrm{~cm}^{-2}$. The reason for this difference is attributed to the fact that the wall thickness of less than $0.5 \mu \mathrm{m}$ in the electrode with $1.2 \mu \mathrm{m}$ pores has a short $\mathrm{Li}^{+}$diffusion distance in solid-state walls. In addition, it is expected that high regularity of 3DOM structure plays a great role on rate capability. Consequently, the 3DOM structure prepared from $1.2 \mu \mathrm{m}$ PS template beads was favorable for improving the rate capability.
\end{abstract}

\section{Introduction}

Lithium ion batteries (LIBs) are now the predominant power sources for portable electronic devices and their performance needs to be increased to meet the energy and power density requirements for transportation systems $[1,2]$. Accordingly, great efforts have been focused on developing alternative materials to component materials used in commercialized LIBs, like lithium alloying materials to carbonaceous negative electrode which has the theoretical capacity limitation of $372 \mathrm{~mA} \mathrm{~h} \mathrm{~g}^{-1}$ lacking for further increasing the energy density and power performance of advanced LIBs [3-5]. Among the negative electrode materials under developing, Sn-based Li alloying materials, one of the most promising candidates for carbonaceous materials, have received much attention and widely examined because of their moderate capacity $\left(\mathrm{Li}_{4.4} \mathrm{Sn}\right.$ : $994 \mathrm{~mA} \mathrm{~h} \mathrm{~g}^{-1}$ ), low potential of about $0.4 \mathrm{~V}$ versus $\mathrm{Li} / \mathrm{Li}^{+}$, and low toxicity [6-8]. Meanwhile, the negative electrodes based on Sn materials also suffer from some fatal problems, like the mechanical instability and poor cycle stability, which were caused by the electrode volume expansion during chargedischarge cycling resulting in the loose contact between active materials and current collector [9-12]. In order to overcome these problems, great efforts have been devoted to design and fabricate Sn-based materials and electrode structures in atomic, submicron, and macro scales.

In the atomic level approaches, many attempts have been made to develop Sn-based alloying materials, including $\mathrm{Cu}$ Sn [9], Ni-Sn [10, 11], and Co-Sn [12]. These materials can be abbreviated as $\mathrm{M}_{x} \mathrm{Sn}_{y}$ in which $\mathrm{M}$ presents Li-inactive element acting as an appropriate buffering matrix for Sn. Giving an overview of them, an alleviation of fatal capacity fade of Sn-based electrodes due to the electrode volume expansion during the charge-discharge process has been achieved more 
or less by controlling the composition of alloying materials $[3,6,9-12]$. In addition to absorbing stress in atomic scale, the alleviation of volume expansion of Sn-based electrodes was also attempted by using submicron scale materials, including fine sized particles with spherical shape, nanowire arrays and materials with microporous structure [13-16]. In particular, materials with microporous structure provide not only the inner space required for nearly free volume expansion but also a large electrochemical interface for $\mathrm{Li}^{+}$insertion and extraction. However, electrodes with such a micro-porous structure also seem to be insufficient to suppress cracking appearance on the electrode surface caused by the volume change during charge-discharge process $[15,16]$. On the other hand, the cracking phenomenon observed on the electrode surface has also guided to develop a technique for preparing a highly patterned electrode in macro scale with microporous structures $[17,18]$.

In our previous work, we have proposed a novel electrode which can relax the volume expansion stress by integrating atomic level buffering effects, microporous structures, and macro patterned electrodes mentioned above. The electrode consists of a highly patterned $\mathrm{Ni}-\mathrm{Sn}$ alloy anode with a 3 dimensionally ordered macroporous (3DOM) structure and has achieved not only high mechanical stability but also high area capacity [18]. The macrosized electrode pattern and the 3DOM structure have been successfully tailored by using photoresist substrate and monodispersed polystyrene (PS) template beads, respectively. The detailed mechanism of how the macrosized pattern and the 3DOM structure influence the mechanical stability is under exploring. On the other hand, the 3DOM structure effects on the rate performance of electrode have not been discussed concretely.

From the viewpoint of LIBs performance, the rate capability of the noble electrode mentioned above is mainly ascribed to $3 \mathrm{DOM}$ structure, including the pore size, interconnecting window size, and wall thickness, and subsequently using the mono-dispersed PS beads with different diameter can easily control the $3 \mathrm{DOM}$ structure. In the present study, we use several mono-dispersed PS beads with different diameters to design and control a 3DOM structure in a highly patterned cylindrical Ni-Sn alloy electrode, and then we examine the effect of the 3DOM structure on the rate capability of the highly patterned electrode for advanced LIBs.

\section{Experimental Methods}

2.1. Material Fabrication. Highly patterned Ni-Sn alloy electrodes with a 3DOM structure were prepared by using a colloidal crystal templating process coupled with an electroplating process on a flexible $\mathrm{Cu}$ current collector patterned with photoresist substrate. The substrate, whose pattern shape is cylinder, was supplied from Tokyo Ohka Kogyo Co., Ltd., and its SEM image can be found elsewhere [17]. The assupplied photoresist substrate was prepared on the flexible $\mathrm{Cu}$ current collector, and the highly patterned cylindrical hole is with $20 \mu \mathrm{m}$ in diameter and $20 \mu \mathrm{m}$ in thickness. The estimated open hole ratio was about $54 \%$.
The monodispersed polystyrene (PS) latex with beads of $0.5,1.2$ and $3.0 \mu \mathrm{m}$ in diameter was used to fabricate colloidal crystal templates, respectively (Seradyn Inc.). The PS bead electrophoretic-deposition in holes of the photoresist substrate was conducted under an electric field of $5 \mathrm{~V} \mathrm{~cm}^{-1}$ for $20 \mathrm{~min}$. Then, heat treatment was carried out at $100^{\circ} \mathrm{C}$ for $8 \mathrm{~min}$ to interconnect the PS beads with the neighbors. Before electroplating Ni-Sn component, the wettability of the PS templates within the photoresist substrate was needed to improve by immersing into a $20 \mathrm{vol} \%$ ethanol aqueous solution for $20 \mathrm{~s}$. Without immersion in the ethanol aqueous solution, the plating solution with the alloy component did not penetrate the PS template well. Ni-Sn alloy was electroplated into the interstices of the PS template in the plating solution containing $0.075 \mathrm{~mol} \mathrm{dm}^{-3} \mathrm{NiCl}_{2} \cdot 6 \mathrm{H}_{2} \mathrm{O}, 0.175 \mathrm{~mol} \mathrm{dm}^{-3} \mathrm{SnCl}_{2} \cdot 2 \mathrm{H}_{2} \mathrm{O}$, $0.5 \mathrm{~mol} \mathrm{dm}^{-3} \mathrm{~K}_{4} \mathrm{P}_{2} \mathrm{O}_{7}$, and $0.125 \mathrm{~mol} \mathrm{dm}^{-3}$ glycine. The $\mathrm{pH}$ of the plating solution was controlled to 8.9 using $26 \% \mathrm{NH}_{4} \mathrm{OH}$ solution. The electroplating was performed under constant current conditions of $1.75 \mathrm{~mA} \mathrm{~cm}^{-2}$ at $50^{\circ} \mathrm{C}$ for $44 \mathrm{~min}$ using an automatic polarization system (HSV-100, Hokuto Denko Corp.). After electroplating, the electrode was immersed into acetone to remove the photoresist substrate and then put into toluene to eliminate the PS template. At last, an Ni-Si alloy electrode with an inverse-opal porous structure and a given alloying composition was obtained.

2.2. Characterizations. Composition of plated Ni-Sn alloy was determined by X-ray fluorescence (XRF, ZSX, RIGAKU). The morphology of prepared Ni-Sn alloy electrodes was observed using a scanning electron microscope (SEM, JSM5310, JEOL). Crystallographic structures were characterized by X-ray diffraction (XRD, RINT-2000, RIGAKU) with Cu Ka radiation.

An electrochemical performance of an electrode prepared with Ni-Sn alloy was characterized by charge and discharge test using an automatic charge-discharge instrument (HJ1001SM8A, HOKUTO DENKO). The Sn-Ni alloy was set in 2032 coin cell with a mixture of ethylene carbonate and diethyl carbonate (volume ratio $=1: 1$ ) containing $1 \mathrm{~mol} \mathrm{dm}^{-3}$ $\mathrm{LiClO}_{4}$ as an electrolyte and with Li metal as a counterelectrode. A charge process $\left(\mathrm{Li}^{+}\right.$insertion into $\mathrm{Ni}-\mathrm{Sn}$ alloy) was performed under the constant current-constant voltage (CC$\mathrm{CV})$ mode, charging at a various constant current density from $0.05 \mathrm{~mA} \mathrm{~cm}^{-2}$ to $2.0 \mathrm{~mA} \mathrm{~cm}{ }^{-2}$ until $0 \mathrm{~V}$ versus $\mathrm{Li} / \mathrm{Li}^{+}$, then charging at a constant voltage of $0 \mathrm{~V}$ until charge capacity reached $600 \mathrm{~mA} \mathrm{~h} \mathrm{~g}^{-1}$. A discharge process $\left(\mathrm{Li}^{+}\right.$extraction from $\mathrm{Sn}-\mathrm{Ni}$ alloy) was carried out at a constant current with the same value in charging process. Cutoff voltages of charge and discharge processes were 0 and $2.5 \mathrm{~V}$, respectively. All the electrochemical measurements were carried out at $30^{\circ} \mathrm{C}$.

\section{Results and Discussion}

3.1. General Considers about Electrochemical Performance and Porous Structures. Generally, for porous electrodes as shown in Figure 1(a), its electrochemical performance is mainly determined by the porous architecture, including 


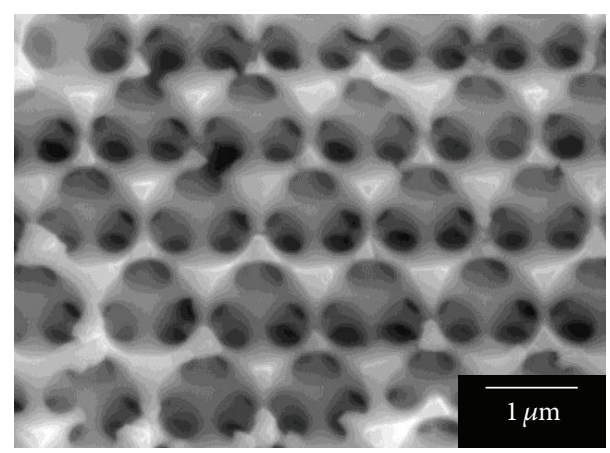

(a)

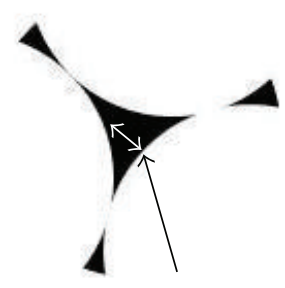

Li ion diffusion distance

(b)

FIGURE 1: SEM image of a 3 dimensionally ordered macroporous electrode prepared with $1.2 \mu \mathrm{m}$ beads (a). (b) Is a schematic illustration of porous structures including walls and interconnecting windows.

pores, interconnecting widows, and walls [19]. For example, the small pore sizes are related to the large surface area available for the electrochemical reaction, relatively big sizes of interconnecting window will favor the $\mathrm{Li}^{+}$ diffusion through electrolyte, and the thin wall thickness will benefit the solid-state $\mathrm{Li}^{+}$diffusion. It should be noted that appropriate interconnecting window size and thinner walls are advantageous at high discharge rate, but not at low rates, when kinetic limitations are less important [19]. On the other hand, there is a difficulty tuning these factors mentioned above for preparing desired electrodes with high performance. In this study, we focused on the $\mathrm{Li}^{+}$diffusion distance through solid-state walls to design the wall thickness with different monodispersed PS template beads. A schematic illustration of a feasible correlation between the rate performance and the wall thickness is presented in Figure 2.

3.2. Properties of Prepared Ni-Sn Alloy Electrodes. The top views of $\mathrm{Ni}-\mathrm{Sn}$ alloy electrodes with a 3DOM structure are presented in Figure 3. In all cases, a highly patterned cylindrical electrode was electrodeposited on the substrate with good reflection of photoresist morphology, as shown in Figures 3(a), 3(c), and 3(e). These SEM images also revealed the formation of the 3DOM structures and those pore sizes highly reflected the PS beads in different diameters used.
Besides the pore morphology in 3DOM structure, a highly ordered interconnect window and wall structure was also confirmed from Figures 3(b), 3(d), and 3(f). The sizes of pore, interconnect window, and wall thickness were increased with increasing the size of PS beads used as colloidal crystal template. Typically, by using particles with different diameter as the template, the wall thickness between macropores can be controlled to about $0.17 \mu \mathrm{m}$ for the electrode using $0.5 \mu \mathrm{m}$ PS beads, $0.45 \mu \mathrm{m}$ for the electrode using $1.2 \mu \mathrm{m}$ PS beads, and $1.0 \mu \mathrm{m}$ for the electrode using $3.0 \mu \mathrm{m}$ PS beads, respectively. It has been reported that a $0.5 \mu \mathrm{m}$ thick Ni-Sn thin film electrode has a large specific capacity and long cycle life [10]. With regard to the $\mathrm{Li}^{+}$diffusion distance and volume change, the wall thickness less than $0.5 \mu \mathrm{m}$ may be favorable for high rate capability of LIBs.

In all cases, a similar XRD pattern is observed for $\mathrm{Ni}$ Sn alloy electrodes with different 3DOM structures. Figure 4 shows the typical XRD pattern of the photoresist substrate and the electrodeposited Ni-Sn alloy electrode. The XRD peaks were attributed to $\mathrm{Ni}_{3} \mathrm{Sn}_{4}, \mathrm{NiSn}$, and $\mathrm{Cu}$ substrate [12]. It was confirmed that $\mathrm{Ni}_{3} \mathrm{Sn}_{4}$ is the predominant phase in the microporous electrode and $\mathrm{NiSn}$ is small enough to be neglected. Moreover, XRF analysis was conducted to confirm the composition of the electro-deposited Ni-Sn alloy electrode and its results revealed that the atomic ratio of $\mathrm{Ni} / \mathrm{Sn}$ was ca. 40/60 in all cases. Mukaibo et al. studied the effect of composition of the Ni-Sn thin film electrode on electrochemical properties. The thin film containing Sn of 62 atom\% showed the highest reversible capacity $[10,11]$. Ni-Sn alloy electrodes prepared in this study were close to their best composition. Therefore, one can expect that the difference in the electrochemical performance of electrodes prepared in this study is mainly attributed to 3DOM structures which were controlled by using different PS beads.

3.3. Electrochemical Performance of Prepared Ni-Sn Alloy Electrodes with Different 3DOM Structures. For electrochemical evaluation of prepared electrodes, we conducted chargedischarge measurements under given conditions. Figure 5 demonstrates the first discharge curves of highly patterned cylindrical Ni-Sn alloy electrode with 3DOM structure at different current density. In all cases, the discharge curves showed a plateau potential around $0.4 \mathrm{~V}$ versus $\mathrm{Li} / \mathrm{Li}^{+}$, indicating that the delithiation process from $\mathrm{Sn}$ in the Ni-Sn alloy electrode smoothly occurred. The gravimetric capacity during the first discharge cycle at the current density of $0.05 \mathrm{~mA} \mathrm{~cm}^{-2}$ was $450 \mathrm{~mA} \mathrm{~h} \mathrm{~g}^{-1}$ for the electrode using $0.5 \mu \mathrm{m}$ beads, $520 \mathrm{~mA} \mathrm{~h}^{-1}$ for the electrode using $1.2 \mu \mathrm{m}$ beads, and $595 \mathrm{~mA} \mathrm{~h} \mathrm{~g}^{-1}$ for the electrode using $3.0 \mu \mathrm{m}$ beads, respectively. Besides the electrode with $1.2 \mu \mathrm{m}$ pores as shown in Figure 5(b), the discharge capacities gradually decreased as increasing the discharge current density (Figures 5(a) and $5(c)$ ), showing the capacity conservation ratio of $87 \%$ for the electrode with $0.5 \mu \mathrm{m}$ pores and that of $84 \%$ for the electrode with $3.0 \mu \mathrm{m}$ pores when discharge current density increased from $0.05 \mathrm{~mA} \mathrm{~cm}^{-2}$ to $2.0 \mathrm{~mA} \mathrm{~cm}^{-2}$. The dependence of discharge capacity conservation ratio on the rate capability 


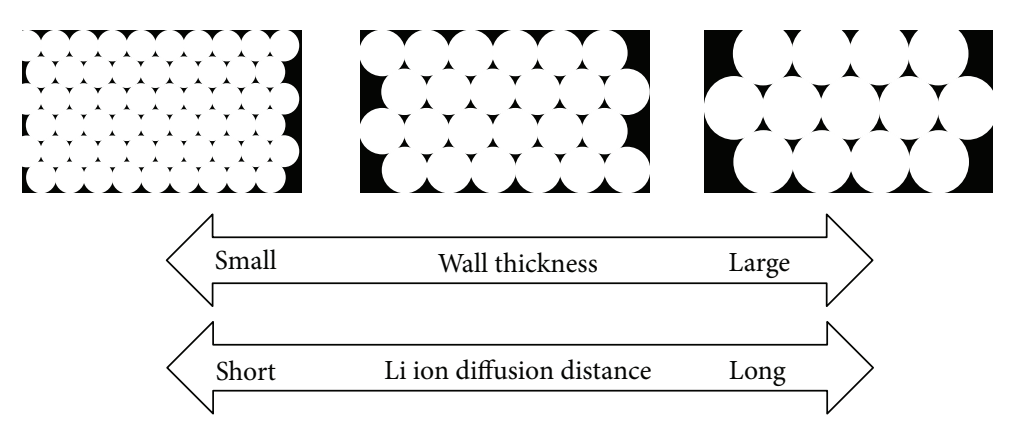

FIGURE 2: Schematic illustration of correlation between 3DOM structure and rate performance.

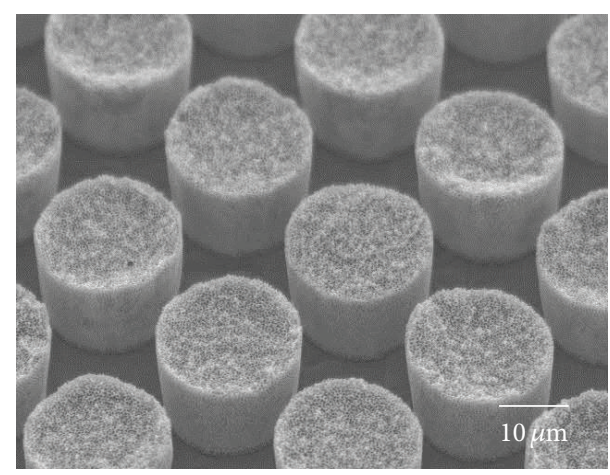

(a)

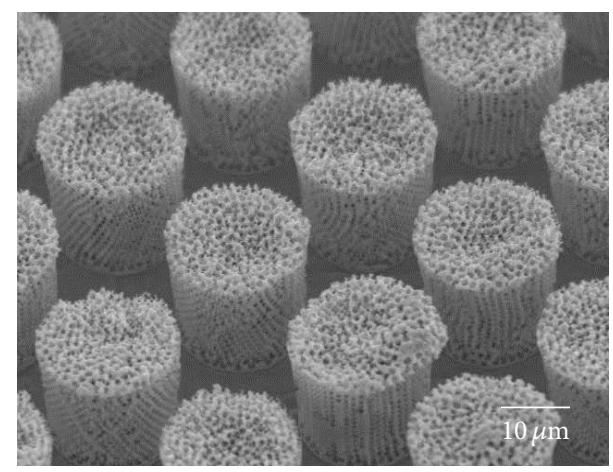

(c)

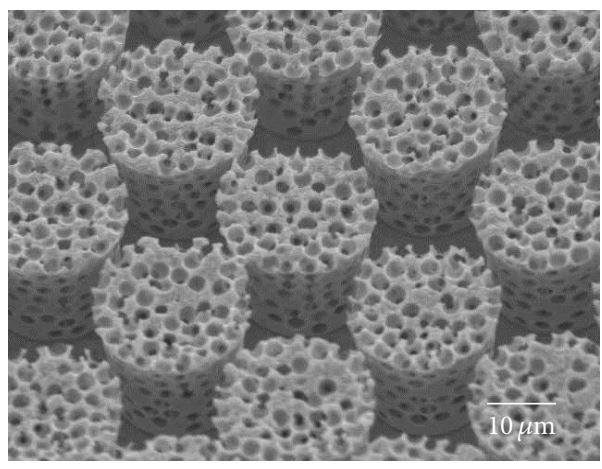

(e)

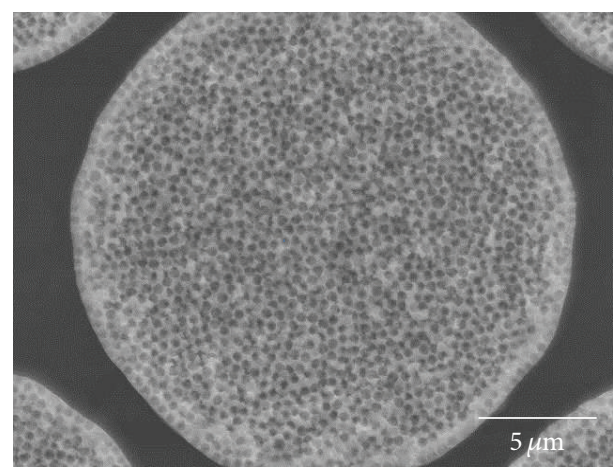

(b)

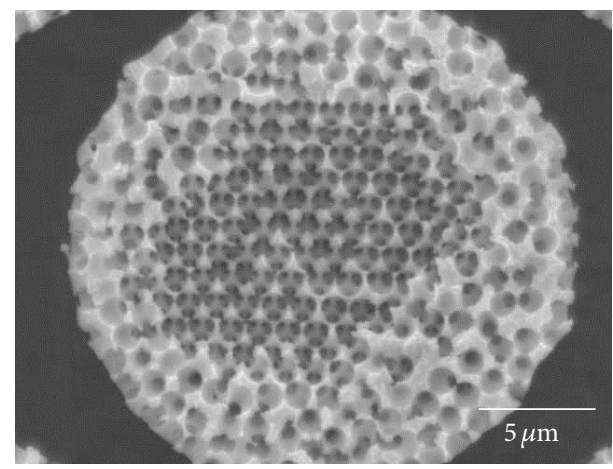

(d)

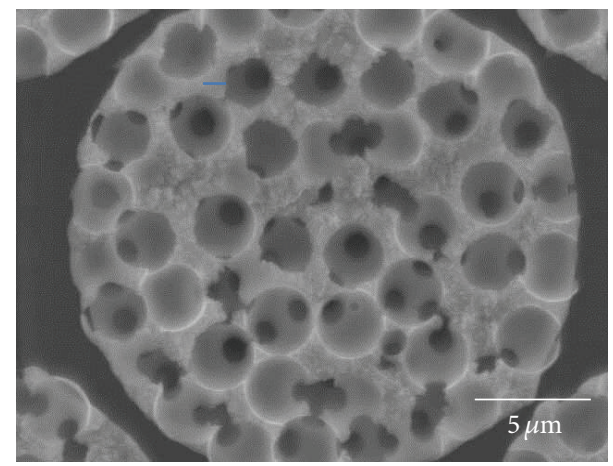

(f)

FIGURE 3: SEM images of 3DOM Ni-Sn alloy electrode with $0.5 \mu \mathrm{m}$ pores (a) and (b), $1.2 \mu \mathrm{m}$ pores (c) and (d), and $3.0 \mu \mathrm{m}$ pores (e) and (f), respectively. 


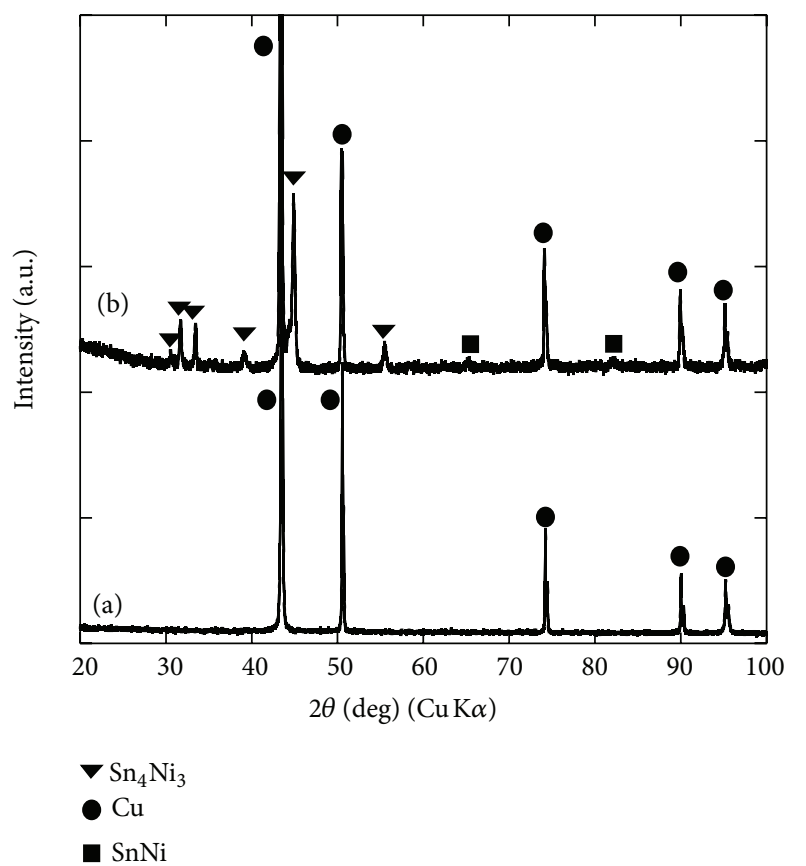

FIGURE 4: A typical XRD pattern of (a) as-prepared photoresist substrate and (b) highly patterned cylindrical Ni-Sn alloy with 3 dimensionally ordered macroporous structure.

would be attributed to different 3DOM structures. One of the reasons for this is attributed to the fact that the wall thickness is less than $0.5 \mu \mathrm{m}$ in the electrode. This threshold applies to the electrodes prepared with $0.5 \mu \mathrm{m}$ and $1.2 \mu \mathrm{m}$ PS beads. However, good rate capability was observed only for the electrode with $1.2 \mu \mathrm{m}$ pores. In detailed comparison of their 3DOM structures shown in Figures 3(b) and 3(d), it is also found that the electrode with $1.2 \mu \mathrm{m}$ pores has a higher regularity in pore distribution than $0.5 \mu \mathrm{m}$-pored one. A higher regularity of electrode structure basically provides a more uniform current distribution that goes with better rate capability. Therefore, a good rate capability observed for $1.2 \mu \mathrm{m}$-pored electrode is expected to be due to highly ordered structure as well as thin wall of 3DOM Ni-Sn.

\section{Conclusion}

Highly patterned cylindrical Ni-Sn alloying electrodes with 3 dimensionally ordered macroporous (3DOM) structures were successfully prepared by using colloidal crystal templating process coupled with electroplating process. The 3DOM structure was tailored with various polystyrene (PS) beads. Scanning electron microscopy observations revealed that the pores size in 3DOM structure is in good agreement with the size of PS template and the wall thickness is increased with increasing the size of PS beads used. The discharge curves of prepared electrodes with different wall thickness and pore regularity showed the $3 \mathrm{DOM}$ structure with $1.2 \mu \mathrm{m}$ pores is most favored for the rate capability of the prepared electrode.

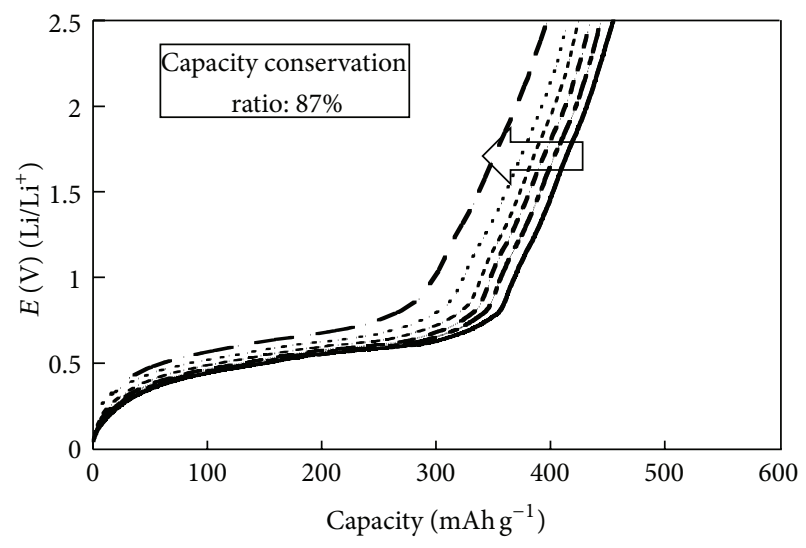

(a)

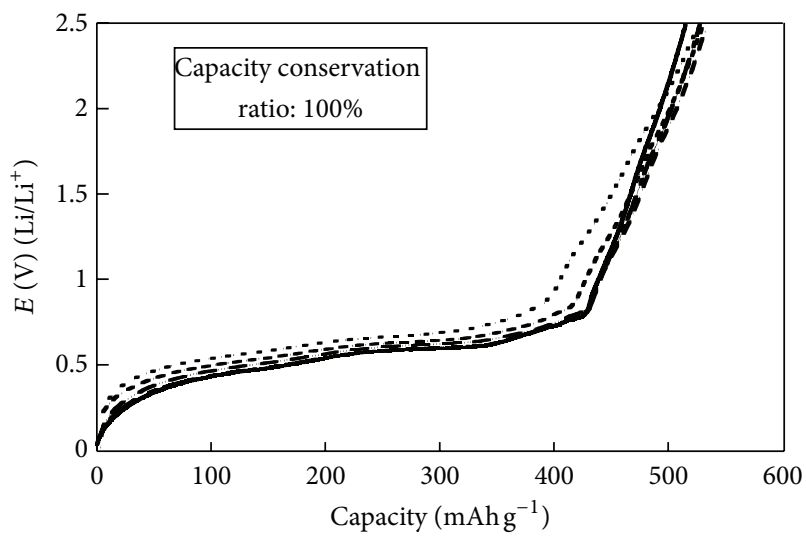

(b)

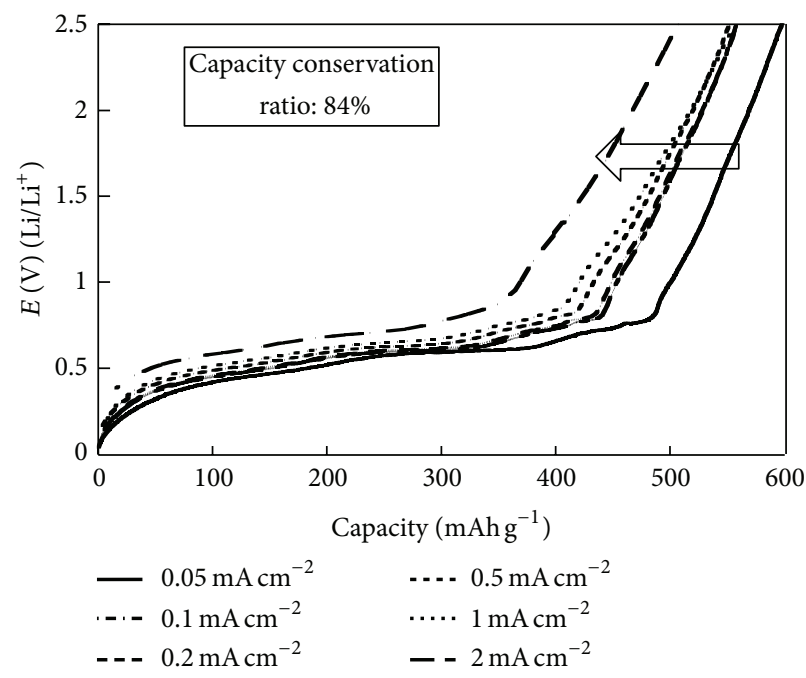

(c)

FIGURE 5: Rate performances of 3DOM Ni-Sn alloy electrode with (a) $0.5 \mu \mathrm{m}$ pores, (b) $1.2 \mu \mathrm{m}$ pores and (c) $3.0 \mu \mathrm{m}$ pores, respectively.

\section{Acknowledgments}

This work was partially supported by "Development of High performance Battery System for Next-generation Vehicles Project" from the New Energy and Industrial Technology Development Organization (NEDO) of Japan. The authors 
especially thank Tokyo Ohka Kogyo Co., Ltd. for their help in preparing photoresist substrates.

\section{References}

[1] B. Scrosati and J. Garche, "Lithium batteries: status, prospects and future," Journal of Power Sources, vol. 195, no. 9, pp. 24192430, 2010.

[2] A. S. Aricò, P. Bruce, B. Scrosati, J. M. Tarascon, and W. Van Schalkwijk, "Nanostructured materials for advanced energy conversion and storage devices," Nature Materials, vol. 4, no. 5, pp. 366-377, 2005.

[3] W. J. Zhang, "A review of the electrochemical performance of alloy anodes for lithium-ion batteries," Journal of Power Sources, vol. 196, no. 1, pp. 13-24, 2011.

[4] A. K. Shukla and T. P. Kumar, "Materials for next-generation lithium batteries," Current Science, vol. 94, no. 3, pp. 314-331, 2008.

[5] M. Winter, J. O. Besenhard, M. E. Spahr, and P. Novák, "Insertion electrode materials for rechargeable lithium batteries," Advanced Materials, vol. 10, no. 10, pp. 725-763, 1998.

[6] R. A. Huggins, "Lithium alloy negative electrodes," Journal of Power Sources, vol. 81-82, no. 1, pp. 13-19, 1999.

[7] M. Winter and J. O. Besenhard, "Electrochemical lithiation of tin and tin-based intermetallics and composites," Electrochimica Acta, vol. 45, no. 1, pp. 31-50, 1999.

[8] D. Larcher, S. Beattie, M. Morcrette, K. Edström, J. C. Jumas, and J. M. Tarascon, "Recent findings and prospects in the field of pure metals as negative electrodes for Li-ion batteries," Journal of Materials Chemistry, vol. 17, no. 36, pp. 3759-3772, 2007.

[9] M. M. Thackeray, J. T. Vaughey, A. J. Kahaian, K. D. Kepler, and R. Benedek, "Intermetallic insertion electrodes derived from NiAs-, $\mathrm{Ni}_{2} \mathrm{In}$-, and $\mathrm{Li}_{2} \mathrm{CuSn}$-type structures for lithiumion batteries," Electrochemistry Communications, vol. 1, no. 1, pp. 111-115, 1999.

[10] H. Mukaibo, T. Sumi, T. Yokoshima, T. Momma, and T. Osaka, "Electrodeposited Sn-Ni alloy film as a high capacity anode material for lithium-ion secondary batteries," Electrochemical and Solid-State Letters, vol. 6, no. 10, pp. A218-A220, 2003.

[11] H. Mukaibo, T. Momma, and T. Osaka, "Changes of electrodeposited Sn-Ni alloy thin film for lithium ion battery anodes during charge discharge cycling," Journal of Power Sources, vol. 146, no. 1-2, pp. 457-463, 2005.

[12] N. Tamura, M. Fujimoto, M. Kamino, and S. Fujitani, "Mechanical stability of Sn-Co alloy anodes for lithium secondary batteries," Electrochimica Acta, vol. 49, no. 12, pp. 1949-1956, 2004.

[13] S. H. Ju, H. C. Jang, Y. C. Kang, and D. W. Kim, "Characteristics of Sn-Ni alloy powders directly prepared by spray pyrolysis," Journal of Alloys and Compounds, vol. 478, no. 1-2, pp. 177-180, 2009.

[14] M. Tian, W. Wang, S. Lee, Y. Lee, and R. Yang, "Enhancing Ni-Sn nanowire lithium-ion anode performance by tailoring active/inactive material interfaces," Journal of Power Sources, vol. 196, no. 23, pp. 10207-10212, 2011.

[15] H. R. Jung, E. J. Kim, Y. J. Park, and H. C. Shin, "Nickel-tin foam with nanostructured walls for rechargeable lithium battery," Journal of Power Sources, vol. 196, no. 11, pp. 5122-5127, 2011.

[16] K. Nishikawa, K. Dokko, K. Kinoshita, S. W. Woo, and K. Kanamura, "Three-dimensionally ordered macroporous Ni-Sn anode for lithium batteries," Journal of Power Sources, vol. 189, no. 1, pp. 726-729, 2009.

[17] S. W. Woo, N. Okada, M. Kotobuki et al., "Highly patterned cylindrical Ni-Sn alloys with 3-dimensionally ordered macroporous structure as anodes for lithium batteries," Electrochimica Acta, vol. 55, no. 27, pp. 8030-8035, 2010.

[18] M. Kotobuki, N. Okada, and K. Kanamura, "Design of a micropattern structure for a three dimensionally macroporous Sn$\mathrm{Ni}$ alloy anode with high areal capacity," Chemical Communications, vol. 47, no. 21, pp. 6144-6146, 2011.

[19] A. Vu, Y. Qian, and A. Stein, "Porous electrode materials for lithium-ion batteries-how to prepare them and what makes them special," Advanced Energy Materials, vol. 2, no. 9, pp. 10561085, 2012. 

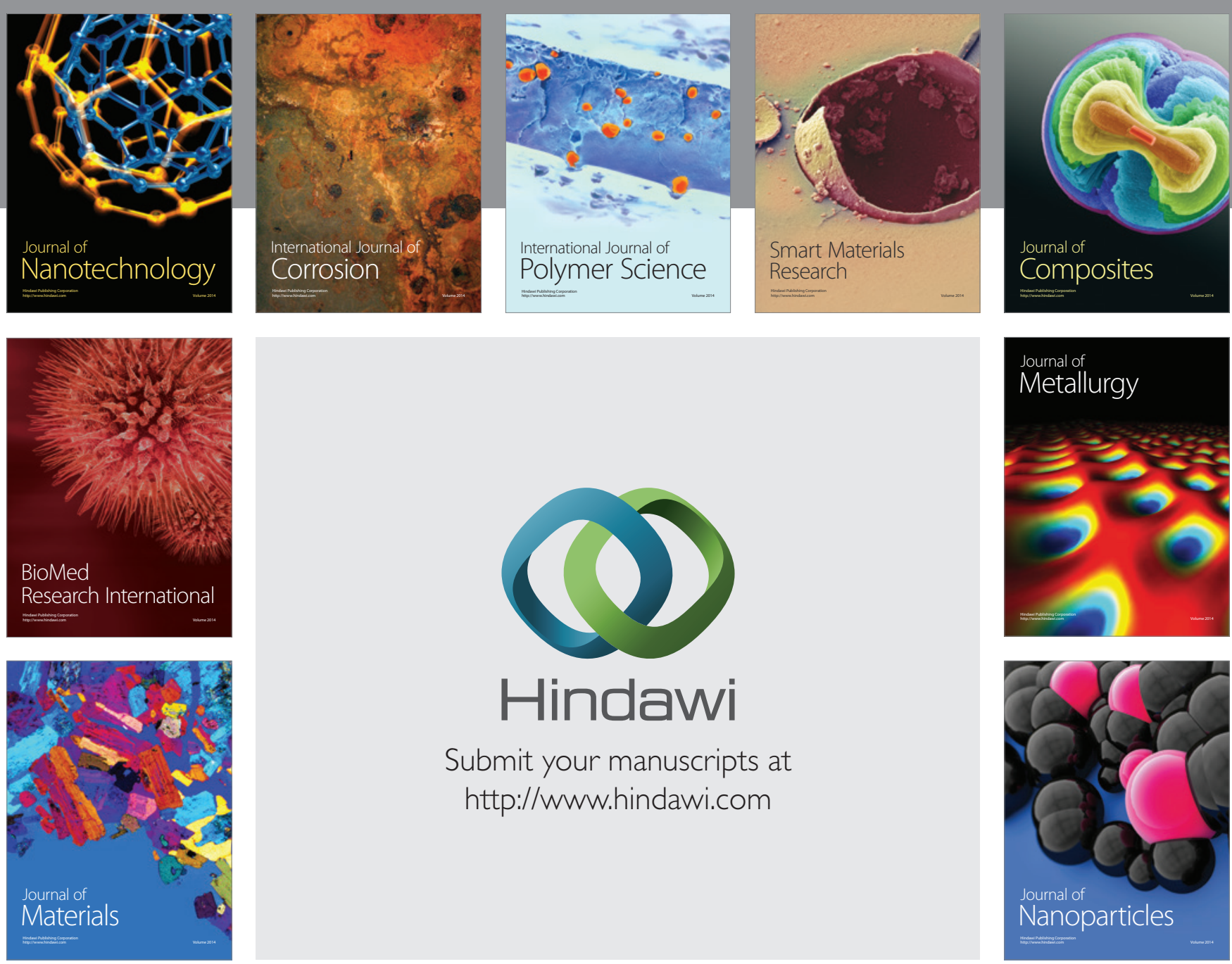

Submit your manuscripts at http://www.hindawi.com
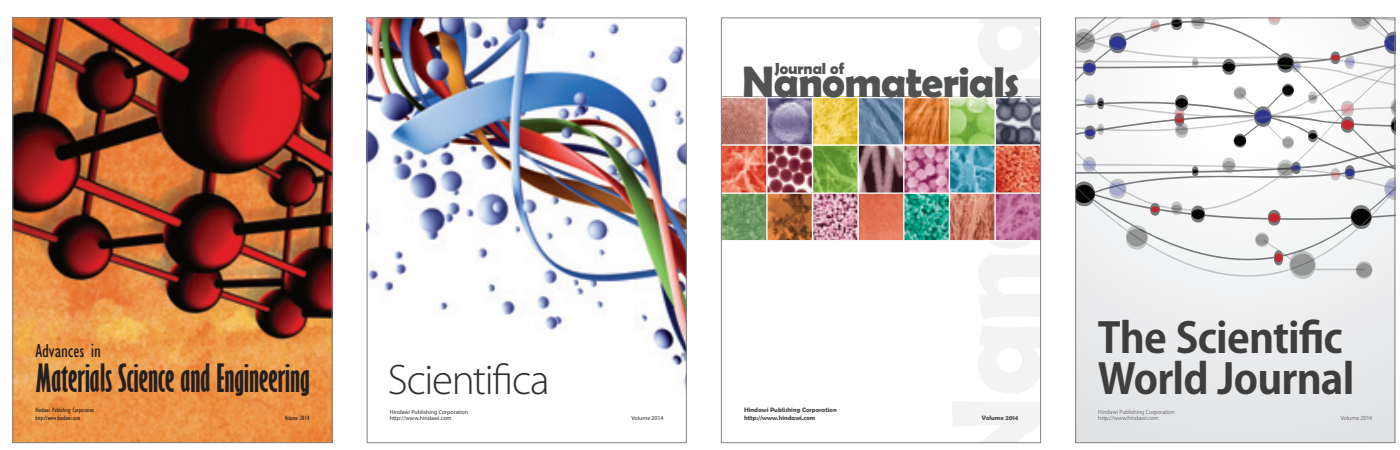

\section{The Scientific World Journal}
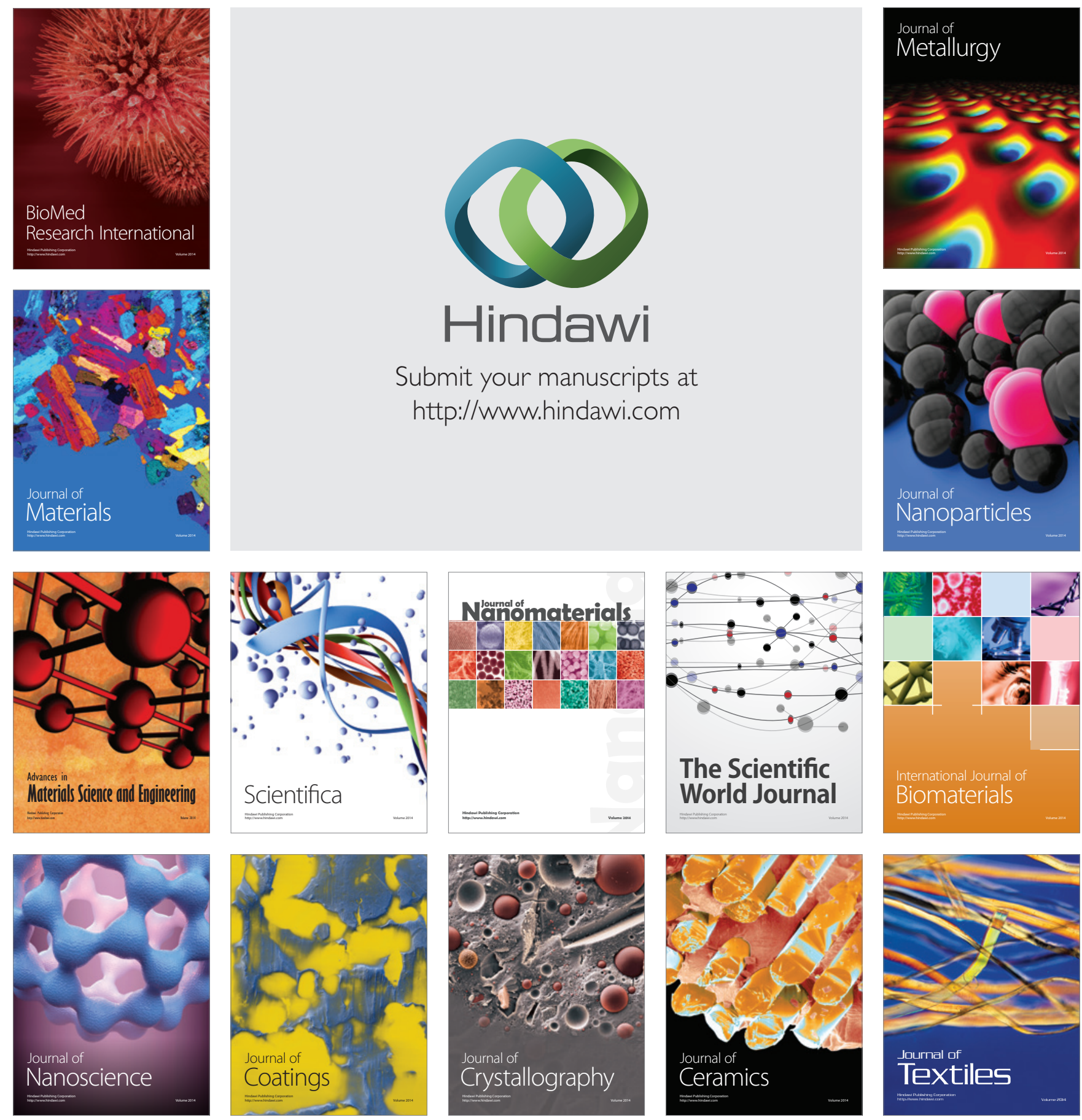